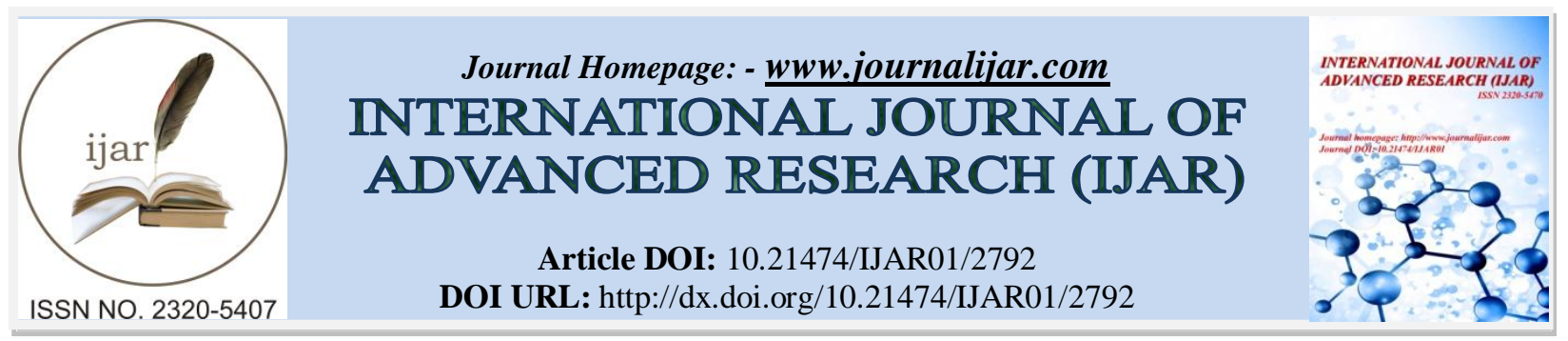

RESEARCH ARTICLE

\title{
DIAGNOSTIC VALUE OF CONVENTIONAL CYTOGENETIC ANALYSIS IN SELECTED CHILDREN WITH ATTENTION-DEFICIT HYPERACTIVITY DISORDER.
}

\author{
Mohamed Abdel Malik Hassan", Ali Alnabawy ${ }^{2}$ and "Shaimaa Abdelmalik Pessar'. \\ 1. Pediatrics Department, Faculty of Medicine, Al-Azhar University, Cairo, Egypt. \\ 2. Psychiatry Department, Faculty of Medicine, Al-Azhar University, Cairo, Egypt. \\ 3. Clinical Pathology Department, Faculty of Medicine, Ain Shams University, Cairo, Egypt.
}

\section{Manuscript Info}

\section{Manuscript History}

Received: 15 November 2016

Final Accepted: 17 December 2016

Published: January 2017

Key words:-

ADHD, Pediatric psychiatry,

karyotyping, chromosomal

abnormalities.

\section{Abstract}

Introduction: Attention deficit hyperactivity disorder (ADHD) is a wide spread, highly heritable, disruptive, childhood-onset condition, the etiology and pathogenesis of which is poorly understood. ADHD in children have been associated with several cytogenetic aberrations. The most remarkable of these include; sex chromosome aneuploidies, fragile X syndrome, velocardiofacial syndrome, certain balanced translocations, and others. Some researchers have suggested that cytogenetic analysis should be considered in children with ADHD. However, most evidence to date suggests that these abnormalities are found with increased frequency in ADHD children with positive family history or abnormal clinical signs. Objective: The main goal of this study is to assess the potential diagnostic value of conventional cytogenetic analysis (karyotyping) in ADHD children with positive family history and / or abnormal clinical signs. Method: Blood samples were obtained from 19 ADHD children (13 boys) with positive family history and / or abnormal clinical signs, and analyzed for the presence of cytogenetic abnormalities using high resolution chromosomal banding. Results: three cases had chromosomal abnormalities. Two of them had numerical sex chromosome abnormalities; one had Klinefelter syndrome (47, XXY), while the other had triple X syndrome (47, XXX). The third case had balanced translocation as follow; [46,XY,t(4;21)(p16;q22.1)]. By comparing these findings with their respective prevalence among live births, there was highly significant statistical difference, which indicates high diagnostic value of karyotyping with these selection criteria. Conclusions: In the presence of abnormal clinical signs or positive family history, the cytogenetic assessments are indicated for children with ADHD as a component of investigations of this disorder.

Copy Right, IJAR, 2016,. All rights reserved.

\section{Introduction:-}

With 5\% prevalence, ADHD is among the most common psychiatric disorders in pediatrics. Moreover its symptoms usually continue throughout adulthood. ${ }^{1}$

Corresponding Author:- Shaimaa Abdelmalik Pessar.

Address:- Clinical Pathology Department, Faculty of Medicine, Ain Shams University, Cairo, Egypt. 
ADHD is described as a disorder of improper levels of attention and / or hyperactivity, which gives rise to hindrance in scholastic, family, and social circumstances. Regarding the clinical presentation, The Diagnostic and Statistical manual of Mental disorders, 5th edition (DSM-V) assigns three ADHD subtypes as: mainly inattentive, mainly hyperactive-impulsive and combined subtypes. ${ }^{2}$

ADHD is a heterogeneous disorder, regarding the clinical presentation, etiology, and pathophysiology. To date, no single factor has been identified as the cause of ADHD, also the etiology of ADHD is not completely clarified. There are developing confirmations for the contribution of hereditary and environmental factors in ADHD etiology. ${ }^{3}$ Most of the ADHD environmental risk factors have negative impact on fetal and infantile wellbeing such as maternal smoking, maternal anemia, breech delivery, prematurity, low birth weight, hypoxic-ischemic encephalopathy, cocaine and alcohol exposure, meningitis, encephalitis, and head trauma. ${ }^{4}$

While ADHD is linked to genetic factors in about $80 \%$ of cases, molecular genetic studies suggest that the genetic architecture of ADHD is complex. Many studies show strong evidence for participation of several genes in the etiology of the ADHD, such as; The Dopamine D4 receptor (DRD4), The Dopamine 5 receptor (DRD5), and The Dopamine Transporter Gene (DAT, SLC6A3). ${ }^{5}$

Despite presence of significant number of syndromes associated with ADHD (include Prader-Willi, Klinefelter, Williams, velocardiofacial, Turner, fragile X, and others), these disorders are infrequently presented among ADHDclinic patients. The prevalence of cytogenetic abnormalities was assessed in ADHD children with normal intelligence, and no significant difference from that expected in the general population had been found. ${ }^{\mathbf{4 , 6}}$

So with lacking of positive family history or abnormal clinical signs, this expensive and time consuming test is not a routine for the children with ADHD. ${ }^{6}$ However, no screening for the diagnostic value of cytogenetic analysis in a population of ADHD children with positive family history or abnormal clinical findings had been performed. The current exploratory study aims to assess the potential diagnostic value of conventional cytogenetic analysis (karyotyping) in ADHD children with positive family history and / or abnormal clinical signs.

\section{Patients and methods:- Study design:-}

A cross-sectional study was conducted at the psychiatric department, El- Hussein Hospital, Al-Azhar UniversityCairo, Egypt, over a period of 5 months from May to September 2016. Informed parental consent was obtained prior to enrollment in the study.

\section{Study population:-}

A sample of 19 ADHD subjects aged between 5-18 years were consecutively enrolled. Each of them must fulfill at least one of the following criteria; 1) positive family history of a major neuropsychiatric disorder (ADHD, autism, mental retardation,....etc), or 2) abnormal clinical finding e.g. epilepsy, short stature, mental retardation, dysmorphic features, ,.....etc. ADHD was diagnosed and categorized according to the DSM-V criteria for diagnosis and grading of ADHD. ${ }^{2}$

Cases that have typical phenotypic features of any specific syndrome or multiple congenital anomalies will be excluded from the study.

\section{Methods:-}

All candidates were subjected to:

History

comprehensive history-taking including; Personal history (age, sex, residence, and school attendance), Perinatal history (complete obstetric and medical history of the mother stressing on prenatal, natal, and postnatal history, including intrauterine exposure to the teratogenic drugs), developmental history (including four major developmental milestones; fine motor, gross motor, social, and language), detailed family history of neurobehavioral disturbance (e.g. learning disability, language delay, autism, schizophrenia, or ADHD), and Medical history for major medical insults e.g. (CMV, meningitis ...etc). 


\section{Clinical examination:-}

A detailed clinical examination was performed including; general examination, chest examination, cardiac examination, abdominal examination, and neurological examination.

\section{Intelligence quotient (IQ) assessment:-}

All the study cases were subjected to IQ assessment using the Arabic version of Stanford-Binet Intelligence Test (SBITA), the fifth edition. ${ }^{7}$ Total IQ quotient was classified into: mentally retarded $(\leq 67)$, borderline intelligence (68-78), below average (79-88), average (89-110), above average (111-120), excellent (121-131) and genius $(\geq$ $132)^{7}$

\section{Conventional Cytogenetic analysis (Karyotyping):- \\ Sample collection and set up:-}

$5 \mathrm{ml}$ of venous blood were collected in heparinised vacutainers from every referred patient for a lymphocyte cell culture. Few drops of the sample were cultured in RPMI 1640 (Biochrom AG, Germany) medium supplemented with fetal calf serum, penicillin/streptomycin, Amphotericin B, and Phytohaemagglutinin (as a mitogenic agent), then incubated at $37^{\circ} \mathrm{C}$ for $72 \mathrm{~h}$. The metaphases were arrested by adding a colchicine derivative (colcemid) (Euroclone) 2 hours prior to the harvest. ${ }^{8}$

\section{Harvesting:-}

At harvest, the culture solution is centrifuged at $800-1000 \mathrm{rpm}$ for 8 minutes. Most of the supernatant of the tubes was discarded leaving only $0.5 \mathrm{ml}$ for resuspention of the cells. This was done by gentle tapping of the tube at the bottom, $10 \mathrm{ml}$ of hypotonic potassium chloride solution $(0.56 \% \mathrm{KCl})$ was added slowly, incubated at $37{ }^{\circ} \mathrm{C}$ for 20 minutes, then centrifuged for 8 minutes at $800-1000 \mathrm{rpm}$, and the supernatant of the tubes was discarded. ${ }^{8}$

After that, $10 \mathrm{ml}$ of freshly prepared fixative solution of a 3:1 mixture of methyl alcohol and glacial acetic acid is added, mixed gently by a clean glass Pasteur pipette and centrifuged for 8 minutes at $800-1000 \mathrm{rpm}$. The supernatant of the tubes was discarded, and the previous step was repeated twice with $10 \mathrm{ml}$ then $5 \mathrm{ml}$ of fixative solution respectively, until the supernatant becomes clear. Then, the culture tubes were left freezed. ${ }^{\mathbf{8}}$

Chromosome staining and banding techniques were performed as described by Benn and Perle. ${ }^{9}$ In every case, 20 cells were counted and at least 5 cells were analyzed, using two separate blood tubes from each patient. If there was any indication for mosaicism, in addition to the mentioned procedure, 200 metaphases were scanned again from that two separate blood tubes. ${ }^{10}$

All karyotypes had been performed using applied software and imaging system and were interpreted according to the International System for Human Cytogenetic Nomenclature (ISCN). ${ }^{11}$

\section{Statistical analysis:-}

Data were analyzed using IBM SPSS Advanced Statistics version 20.0 (IBM Corp., Armonk, NY, USA). Numerical data were expressed as mean, standard deviation, and range. Qualitative data were expressed as frequency and percentage. Chi-square test was used to examine the relation between the qualitative variables. The odd ratio (OR) is describing the strength of association or non-independence between two binary data values. Confidence interval (CI) is used to find the margins of accuracy given by a survey's sample size and results, for a chosen confidence level. The Z-value is a test statistic for Z-tests that measures the difference between an observed statistic and its hypothesized population parameter in units of the standard deviation. $\mathrm{p}$-value $<0.05$ was considered statistically significant.

\section{Results:-}

After reviewing 185 children with ADHD, consecutive enrollment of 19 cases in the study was done according to the inclusion criteria as follow; 10 cases had positive family history of major neuropsychiatric disorder [positive family history of; ADHD (6 cases), autism (3 cases), and mental retardation ( 1 case)] ,8 cases had abnormal clinical findings [tall stature (1 case), short stature (1 case), cryptorchidism (1 case), mental retardation ( 2 cases), obesity (1 case), large head ( 1 case), and epilepsy (1 case)], and 1 case had both positive family history (autistic mother) and positive clinical findings (proband was mentally retarded). The age of the study population varied between 5 to 18 years of age (Mean $\pm \mathrm{SD}=9.63 \pm 4.09$ years), and the IQ among them (Mean $\pm \mathrm{SD}=76.63 \pm 12.16649$ ). Other criteria of the study population are shown in table 1 . 
Table (1):- Criteria of the study population.

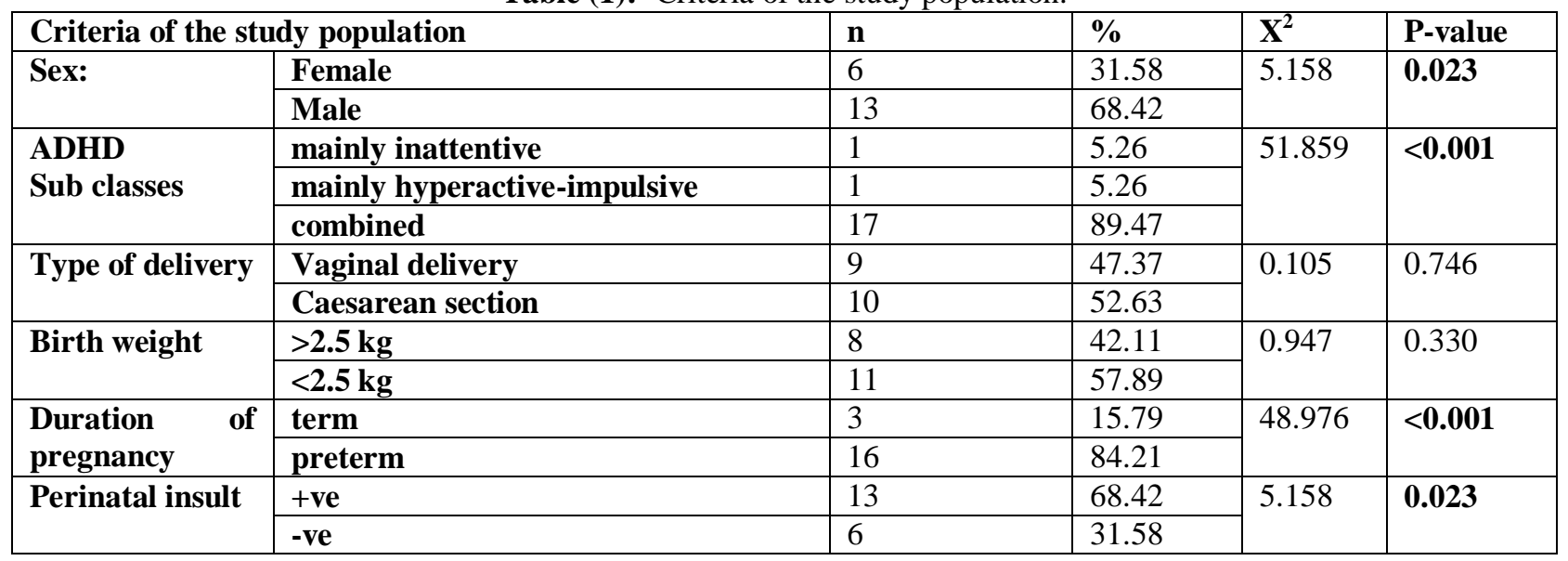

Out of 19 patients that were karyotyped using conventional G-banding technique, three had chromosomal abnormalities. Two of them had sex chromosome aneuploidies SCA; one had Klinefelter syndrome (47, XXY) (fig. 1), while the other had triple X syndrome (47, XXX) (fig. 2). The third patient had structural autosomal abnormality in the form of balanced translocation between chromosome 4 and chromosome 21, with breaks in 4 p16 and $21 q 22.1$ $[46, \mathrm{XY}, \mathrm{t}(4 ; 21)(\mathrm{p} 16 ; \mathrm{q} 22.1)]$ (fig. 3).

Comparing our prevalence of major chromosomal abnormalities 3/19 (15.79\%) to the expected prevalence of such abnormalities among live births $1 / 140(0.714 \%)^{\mathbf{1 2}}$, there is significant statistical difference $(\mathrm{p}=0.0059)$.

Also, our prevalence of sex chromosome aneuploidies 2/19 (10.53\%) to the expected prevalence of these abnormalities among live births $1 / 426(0.234 \%)^{\mathbf{1 3}}$, there is significant statistical difference $(\mathrm{p}=0.0017)$.

Furthermore, our prevalence of balanced translocations $1 / 19(5.26 \%)$ to the expected prevalence of these abnormalities among live births $1 / 500(0.2 \%)^{\mathbf{1 4}}$, there is significant statistical difference $(\mathrm{p}=0.0206)$.

Table (2):- Comparison between prevalence of chromosomal aberrations among the study population, and general population.

\begin{tabular}{|c|c|c|c|c|c|c|}
\hline \multicolumn{3}{|c|}{ Karyotype results } & Odd ratio & $95 \% \mathrm{CI}$ & z score & p-value \\
\hline \multirow{2}{*}{$\begin{array}{l}\text { Major } \\
\text { chromosomal } \\
\text { abnormalities }\end{array}$} & $\begin{array}{l}\text { Study cases } \\
\text { (+ve/total) }\end{array}$ & $3 / 19$ & \multirow[t]{2}{*}{0.0384} & \multirow[t]{2}{*}{0.0038 to 0.3911} & \multirow[t]{2}{*}{2.753} & \multirow[t]{2}{*}{0.0059} \\
\hline & $\begin{array}{l}\text { General population } \\
\text { (+ve/total) }\end{array}$ & $1 / 140$ & & & & \\
\hline \multirow{2}{*}{$\begin{array}{l}\text { Sex } \\
\text { chromosome } \\
\text { abnormalities }\end{array}$} & $\begin{array}{l}\text { Study cases } \\
\text { (+ve/total) }\end{array}$ & $2 / 19$ & \multirow[t]{2}{*}{0.0200} & \multirow[t]{2}{*}{0.0017 to 0.2315} & \multirow[t]{2}{*}{3.131} & \multirow[t]{2}{*}{0.0017} \\
\hline & $\begin{array}{l}\text { General population } \\
\text { (+ve/total) }\end{array}$ & $1 / 426$ & & & & \\
\hline \multirow[t]{2}{*}{$\begin{array}{l}\text { Balanced } \\
\text { translocation }\end{array}$} & $\begin{array}{l}\text { Study cases } \\
\text { (+ve/total) }\end{array}$ & $1 / 19$ & \multirow[t]{2}{*}{0.0361} & \multirow[t]{2}{*}{0.0022 to 0.6000} & \multirow[t]{2}{*}{2.316} & \multirow[t]{2}{*}{0.0206} \\
\hline & $\begin{array}{l}\text { General population } \\
\text { (+ve/total) }\end{array}$ & $1 / 500$ & & & & \\
\hline
\end{tabular}

The subject with a chromosomal abnormality (47,XXY) was enrolled in the study due to unilateral left sided cryptorchidism, otherwise he was clinically indistinguishable from the other cases. He had below average intelligence $(\mathrm{IQ}=85)$. He was delivered by caesarian section at 37 weeks of gestation, weighing $2,700 \mathrm{~kg}$. Development during infancy passed with unremarkable events. He had combined subtype of ADHD. At the time of enrollment in this study, he was 7 years old and atteneded regular schools.

While the subject with a chromosomal abnormality $(47, \mathrm{XXX})$ was enrolled in the study due to tall stature (height > 2SD), otherwise she was clinically indistinguishable from the remaining probands. She had below average intelligence $(\mathrm{IQ}=88$ ). She was delivered by normal vaginal delivery at 35 weeks of gestation, weighing $2,400 \mathrm{~kg}$. Development during infancy passed within ordinary limits except for language delay, where her first plain word spoken after 20 months. Pubertal onset and sexual development occures normaly (Menarche at the age of 12.5 
years). She had mainly inattentive subtype of ADHD. At the time of enrollment in this study, she was 15 years old and atteneded regular schools.

The only subject with autosomal structural balanced chromosomal aberration [46,XY,t(4;21)(p16;q22.1)] was enrolled in the study with positive family history of autistic mentally subnormal mother and the proband himself was mentally retarded $(\mathrm{IQ}=65)$, without dysmorphic features. He was delivered by normal vaginal delivery at 37 weeks of gestation, weighing 2,800 kg. Development during infancy was globally delayed, where his first plain word spoken after 30 months, walking at 21 months. He had combined subtype of ADHD. At the time of enrollment in the study, he was 9 years old and attended special schools. The proband's parents accepted the option of being tested. The proband's mother has the same translocation.

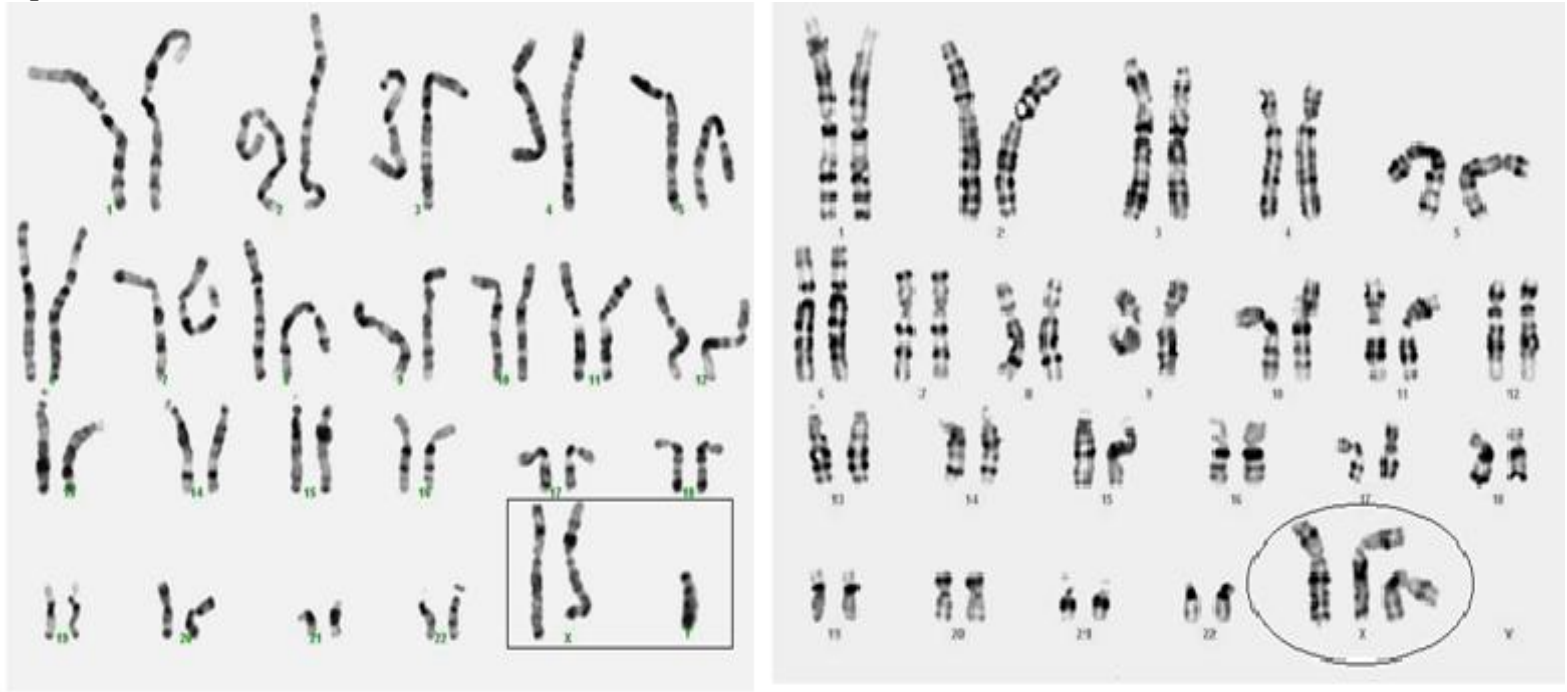

Figure (1)

Figure (1): Klinefelter syndrome (47, XXY).

Figure (2): triple $X$ syndrome (47, XXX) (fig. 2).

Figure (3): balanced translocation $[46, \mathrm{XY}, \mathrm{t}(4 ; 21)(\mathrm{p} 16 ; \mathrm{q} 22.1)]$.

\section{Discussion:-}

Among 19 children with ADHD selected according to the inclusion criteria and enrolled in this study, 6 cases were females while 13 cases were males. Our study showed significant statistical difference between male to female ratio $(p=0.023)$, which was also observed in several studies. ${ }^{15,16}$ However, other studies lacked such difference. ${ }^{17,18}$ The combined type was the commonest ADHD subtype among our cases 17/19 ( $<<0.001)$, where comparable results were described in several other studies. ${ }^{\mathbf{1 6 , 1 9 , 2 0}}$ 
Also, we found statistically significant difference between the proportion of the ADHD children with history of premature delivery compared with term children $(\mathrm{p}<0.001)$. Analogous studies found that preterm children have higher risk for ADHD. ${ }^{21,22}$

Our results revealed statistically insignificant higher proportions of ADHD among low birth weight children $(\mathrm{p}=$ 0.330), which make a matter of controversy with Valdimarsdottir et al. who reported statistically significant increased risk for ADHD associated with low birth weight. ${ }^{23}$

Significant statistical difference between ADHD children with positive past history of perinatal insult in comparison to those lacking such history had been reported in our study $(\mathrm{p}=0.023)$. Despite presence of several perinatal insults that associated with an increased risk for multiple neurologic sequelae, these perinatal risk factors have not been investigated sufficiently in relation to ADHD. ${ }^{\mathbf{2 4 2 5}}$

In this study, conventional cytogenetic assessment identified three children with chromosomal aberrations; two cases with sex chromosome aberrations [one had Klinefelter syndrome (47, XXY), while the other had triple X syndrome $(47, \mathrm{XXX})]$ and single case with balanced translocation between chromosome 4 and chromosome $21[46, \mathrm{XY}, \mathrm{t}(4 ; 21)(\mathrm{p} 16 ; \mathrm{q} 22.1)]$.

Our results were in agreement with the vast majority of studies that concerned with sex chromosomes aneuploidies SCA: (e.g. XXY, XXX, XYY, and XXYY). These studies stated that children and adolescents with SCA are at increased risk for ADHD symptoms. ${ }^{\mathbf{6 , 2 6}}$

In agreement with our findings, Pacenza et al. stated that cryptorchidism is the commonest prepubertal presentation of Klinefelter syndrome. ${ }^{27}$ Also, our findings were well matched with many studies that concerned with triple $\mathrm{X}$ syndrome; where their conclusions told that one of the early remarkable presentations among those patients is a tall stature, furthermore pubertal onset and sexual development are usually normal among them. ${ }^{28}$

Many cytogenetic literatures and studies stated that, about $6 \%$ of balanced translocation carriers have a wide range of behavioral disorders, and intellectual disability. A gene disrupted or deregulated at the breakpoint of the translocation is likely the cause of these symptoms. This is similar to our findings in our proband with balanced translocation. ${ }^{14}$

The break point of our proband $[46, \mathrm{XY}, \mathrm{t}(4 ; 21)(\mathrm{p} 16 ; \mathrm{q} 22.1)]$, which at 4p16 was described in other literatures and researches as one of the top three risk loci for Parkinson's disease. ${ }^{29}$ Despite that no previous direct link between the 4p16 locus and the ADHD but, both Parkinson disease and ADHD originate from dopaminergic system disturbance ${ }^{5}$, which makes this locus one of the supposed gene loci for ADHD for further evaluation.

Despite absence of data about previous studies that screened for the diagnostic value of cytogenetic analysis in ADHD children with positive family history or abnormal clinical findings, Bastain et al. study assessed the prevalence of cytogenetic abnormalities in an unselected population of 100 children with ADHD and IQ $>80$. Only one subject had a clear cytogenetic abnormality (a girl with trisomy 47, XXX), and this did not differ significantly from that expected in the general population $(1 / 426)(\mathrm{p}=0.21)$. The conclusion of Bastain et al. study showed that in the absence of clinical signs or positive family history, these relatively expensive laboratory assessments are not clinically indicated. ${ }^{6}$

Regarding our prevalence of balanced translocations $1 / 19(5.26 \%)$ to the expected prevalence of these abnormalities among live births $1 / 500(0.2 \%)$, there is statistically significant difference (odd ratio=0.0361, 95\% $\mathrm{CI}=0.0022$ to $0.6000, \mathrm{p}=0.0206)$. Also, comparison between our prevalence $(2 / 19)$ and the expected prevalence of sex chromosome abnormalities in general population (1/426) revealed highly significant difference (odd ratio $=0.0200,95 \% \mathrm{CI}=0.0017$ to $0.2315, \mathrm{p}=0.0017$ ).

As a whole, our prevalence of major chromosome abnormalities (3/19) in comparison to their expected prevalence in general population (1/140) was highly significant (odd ratio=0.0384, 95\% CI=0.0038 to 0.3911, $\mathrm{p}=0.0059$ ). These findings indicate high diagnostic value of karyotyping with this selection criteria. 
In conclusion, This study indicates higher diagnostic value of karyotyping among ADHD children with positive family history and/ or abnormal clinical finding. Therefore, meticulous history taking, and examination by expert pediatrician are mandatory to select ADHD cases indicated for cytogenetic analysis.

\section{Conflict of interest:-}

The authors declare no conflict of interest.

Limitations:-

The low rates of the genetic abnormalities we studied is the primary limitation that can be applied to this study.

- We excluded ADHD children with typical phenotypic features of any specific syndrome or multiple congenital anomalies from the study, which decreased the likelihood of detecting chromosomal abnormalities.

- Sample size is low (only 19 cases). But we had reviewed 185 out clinic ADHD children to get these cases in respect of inclusion and exclusion criteria. In addition, we had limited resources regarding this expensive investigation.

\section{References:-}

1. Bădescu GM1, Fîlfan M, Sandu RE, Surugiu R, Ciobanu O, Popa-Wagner A. Molecular mechanisms underlying neurodevelopmental disorders, ADHD and autism. Rom J Morphol Embryol. 2016;57(2):361-6. PMID: 27516006

2. American Psychiatric Association. Diagnostic and statistical manual of mental disorders, 5th edition. Washington: American Psychiatric Association, 2013.

3. Thapar A and Cooper M. Attention deficit hyperactivity disorder. The Lancet. 2016Mar;387(10024):1240-50. DOI: http://dx.doi.org/10.1016/S0140-6736(15)00238-X

4. Millichap JG. Etiologic classification of attention-deficit/hyperactivity disorder. Pediatrics. 2008 Feb;121(2):e358-65. doi: 10.1542/peds.2007-1332.

5. Faraone $\boldsymbol{S V}$ and Mick $\boldsymbol{E}$. Molecular Genetics of Attention Deficit Hyperactivity Disorder. Psychiatr Clin North Am. 2010Mar;33(1):159-180. doi: 10.1016/j.psc.2009.12.004.

6. Bastain TM, Lewczyk CM, Sharp WS, et al. Cytogenetic abnormalities in attention-deficit/hyperactivity disorder. J Am Acad Child Adolesc Psychiatry. 2002;41:806-810. PMID:12108805

7. Farag S. The Stanford-Binet Intelligence Scale: Arabic Examiner's Handbook, 5th ed. Cairo: Anglo Egyptian Bookshop, 2011.

8. Gosden CM, Davidson C, Robertson M. Lymphocyte culture. In: Rooney DE, Czepulkowski BH, editors. Human Cytogenetic: A Practical Approach. 2nd Ed. 4th vol. New York, USA: Oxford IRL Press; 1992. pp. 3154.

9. Benn PA, Perle MA. Chromosome staining and banding. In: Rooney DE, Czepulkowski BH, editors. Human Cytogenetic: A Practical Approach. 2nd ed. 4th vol. New York, USA: Oxford IRL Press; 1992. pp. 91-118.

10. Seabright M. A rapid banding technique for human chromosomes. Lancet. 1971;2:971-972.

11. Shaffer LG, Slovak ML, Campbell LJ. An International System for Human Cytogenetic Nomenclature (ISCN) Basel, Switzerland: S. Karger Publishers, Inc.; 2009.

12. Hsu LYF. Prenatal diagnosis of chromosomal abnormalities through amniocentesis. In: Genetic disorders and the fetus, 4th ed, Milunsky A (Ed), The Johns Hopkins University Press, Baltimore 1998. p.179.

13. Nielsen J, Wohlert M. Chromosome abnormalities found among 34,910 newborn children: results from a 13year incidence study in Arhus, Denmark. Hum Genet. 1991;87:81-83

14. Caroline Mackie Ogilvie; Paul N Scriven. "Meiotic outcomes in reciprocal translocation carriers ascertained in 3-day human embryos". European Journal of Human Genetics. European Society of Human Genetics. December 2002;10 (12): 801-806. doi:10.1038/sj.ejhg.5200895. PMID 12461686.

15. Amiri S, Fakhari A, Maheri M, Mohammad A. Attention deficit/hyperactivity disorder in primary school children of Tabriz, North-West Iran. Pediatric Periapt Epidemiol 2010;24:597-601.

16. Cardo E, Bustillo M, Servera M. The predictive value of DSM-IV criteria in the diagnosis of attention deficit hyperactivity disorder and its cultural differences. Rev Neurol 2007; 44: 19-22.

17. Kashala E, Tylleskar T, ElgeKayembe KT, and Sommerfelt K. Attention Deficit Hyperactivity Disorder Among School Children in Kinshasa, Democratic Republic of Congo, Afr Health Sci 2005; 5: 172-181.

18. Montiel-Nava C, Montiel-Barbero I, Peña JA. Clinical presentation of Attention deficit hyperactivity disorder as a function of the gender. Invest Clin 2007; 48:459-68.

19. Pelham WE, Fabiano GA, Massetti GM. Evidence-based assessment of attention-deficit hyperactivity disorder in children and adolescents. J. Clin Child Adolesc Psychol 2006;34: 449-476. 
20. Possa A, Spanemberg L, Guardiola A. Attention-deficit hyperactivity disorder co-morbidity in a school sample of children. Arq Neuropsyquiatria 2005; 63:479-83.

21. Farooqi A, Hagglof B, Sedin G, Gothefors L, Serenius F. Mental health and social competencies of 10 to 12 year old children born at 23 to 25 weeks of gestation in the 1990s: a Swedish national prospective follow-up study. Pediatrics 2007;120:118 -133.

22. Delobel-Ayoub M, Arnaud C, White-Koning M, Casper C, Pierrat V, Garel M, et al. Behavioral problems and cognitive performance at 5 years of age after very preterm birth: the EPIPAGE Study. Pediatrics 2009; 123:1485-1492.

23. Valdimarsdottir M, Hrafnsdottir AH, Magnosson P. The frequency of some factors in pregnancy and delivery for Icelandic children with ADHD. Laeknabladid 2006; 92:609-614.

24. Lou H. C. Etiology and pathogenesis of attention-deficit hyperactivity disorder (ADHD): significance of prematurity and perinatal hypoxic-haemodynamic encephalopathy. Acta Paediatrica. 1996;85(11):1266-1271. doi: 10.1111/j.1651-2227.1996.tb13909.x.

25. Lindstrom K, Lindblad F, Hjern A. Preterm Birth and Attention-Deficit/Hyperactivity Disorder in Schoolchildren.Pediatrics 2011; 127: 858 -865.

26. Tartaglia NR, Ayari N, Hutaff-Lee C, Boada R. Attention-deficit hyperactivity disorder symptoms in children and adolescents with sex chromosome aneuploidy: XXY, XXX, XYY, and XXYY. J Dev Behav Pediatr. 2012 May;33(4):309-18. doi: 10.1097/DBP.0b013e31824501c8.

27. Pacenza N, Pasqualini T, Gottlieb S, et al. Clinical Presentation of Klinefelter's Syndrome: Differences According to Age International Journal of Endocrinology. Volume 2012, Article ID 324835. doi:10.1155/2012/324835

28. Tartaglia NR, Howell S, Sutherland A, Wilson R, Wilson L. A review of trisomy X (47,XXX). Orphanet J Rare Dis. 2010 May 11;5:8. doi: 10.1186/1750-1172-5-8.

29. Nagle MW, Latourelle JC, Labadorf A, Dumitriu A, Hadzi TC, Beach TG, Myers RH. The 4p16.3 Parkinson Disease Risk Locus Is Associated with GAK Expression and Genes Involved with the Synaptic Vesicle Membrane. PLoS One. 2016 Aug 10;11(8):e0160925. doi: 10.1371/journal.pone.0s160925. eCollection 2016. 